\title{
YAPI MALZEMESİ ÜRETİMİNDE GENLEŞTİRİLMİŞ PERLİT AGREGASI KULLANILABİLİRLİĞİNİN ARAŞTIRILMASI
}

\author{
Atila Gürhan ÇELIK*, Ahmet Mahmut KILIÇ** , Fatih AKKURT \\ *BOREN(Ulusal Bor Araştırma Enstitüsü) Ankara/Türkiye \\ ${ }^{* *}$ Ç.Ü. Maden Mühendisliği Bölümü Adana/Türkiye \\ atila@boren.gov.tr, kilicm@cu.edu.tr, fatih@boren.gov.tr
}

(Geliş/Received: 20.05.2013; Kabul/Accepted: 09.05.2014)

ÖZET

$\mathrm{Bu}$ çalışmanın amacı ana hammadde olarak genleştirilmiş perlit agregası kullanarak duvar örgü elemanı üretilebilirliğinin araştırılmasıdır. Bu amaçla üretilen kontrol numunesinin (50x100x100 mm ebadında) birim hacim ağırlık (BHA), mekanik özellikler gibi mühendislik özellikleri ile beraber, üretim parametreleri (pişme süresi, pişme sıcaklığı, sıkıştırma basınç oranı, kimyasal katkı oranı, boyut analizi ve su/katı oranı) belirlenerek optimize edilmiştir. Sıkıştırma basıncı, pişme sıcaklığı, pişme süresi, bekleme (kür) süresi gibi tasarım parametreleri değiştirilerek, numune üretimi için en etkin değerler belirlenmiştir. Çalışmalar sonucunda, su/katı oranı 1,0 olan, 50 bar basınçta üretilen ve $200^{\circ} \mathrm{C}$ sıcaklıkta 1 saat süreyle pişirilen numunelerden en düşük birim hacim ağırlık $522,5 \pm 48,3 \mathrm{~kg} / \mathrm{m}^{3}$ ve en yüksek basınç dayanımı $12,13 \pm 0,13 \mathrm{~kg} / \mathrm{cm}^{2}$ olarak tespit edilmiştir. Ancak, doğal bağlayıcı kullanmadan üretilen kontrol numune için elde edilen basınç dayanımı değerleri TS EN 771-1 sınır değerlerinin altında bulunmuştur.

Anahtar Kelimeler: Genleştirilmiş perlit agregası, Yapı malzemesi, Basınç dayanımı, Pişme sıcaklığı

\section{INVESTIGATION OF AVAILABILITY OF EXPANDED PERLITE IN THE PRODUCTION OF CONSTRUCTION MATERIAL}

\begin{abstract}
The aim of this study is investigation of wall stone reproducibility using expanded perlite aggregate as a main raw material. For this purpose, production parameters (burning period, burning temperature, pressing pressure ratio, chemical additive ratio, dimension analysis and water/solid (w/s) ratio and also engineering parameters such as weight per unit of volume, mechanical properties of produced control brick (with a dimension of $50 \times 100 \times 100 \mathrm{~mm}$ ) were determined and optimized. The most effective values for the brick production were designated by changing optimization parameters like pressing pressure, burning temperature, burning period, holding (curing) time. As a result of the study, the lowest value of weight per unit of volume and the highest value of compressive strength were ascertained as $522.5 \pm 48.3 \mathrm{~kg} / \mathrm{m}^{3}$ and $12.13 \pm 0.13 \mathrm{~kg} / \mathrm{cm}^{2}$ respectively for the samples which were produced at 50 bar pressure and $200^{\circ} \mathrm{C}$ temperature with $1 \mathrm{~h}$ burning period and w/s ratio of 1.0. However, obtained compressive strength values for the control sample produced without using binder were found to lower the standards of TS EN 771-1.
\end{abstract}

Keywords: Expanded perlite aggregate, Construction material, Compressive strength, Burning temperature

\section{GIRİS (INTRODUCTION)}

Türkiye'de farklı kum, çakıl, çimento, alçı, kireç, perlit, pomza vb. malzemelerden üretilen tuğla, bims, gaz beton ve izotuğla gibi hafif yapı malzemelerinin kullanımı giderek yaygınlaşmaktadır. Ülkemizin deprem kuşağında yer alması, yalıtım parametrelerinin giderek gelişmesi, enerji ihtiyacının giderek yaygınlaşması ve binalarda yalıtımın zorunlu hale gelmesi ile birlikte hafif yapı malzemelerinin üretimi için alternatif ve ucuz kaynaklara yönelim giderek artmaktadır [1,2]. Çobanlı yaptığ genleştirilmiş perlit, kil ve bor atığ 1 kullanarak üretilen panellerin yüksek 1sı yalıtımına sahip, yangına ve dona dayanımının yüksek olduklarını tespit etmiştir [3]. Ayberk tarafından yapılan 
çalışmada; perlitin, yalıtım ve yangına dayanım özellikleri ile yapılarda farklı kullanımlarının olduğu ve perlitin, yapıya az yük vermesi, alan kazandırması ve yakıt tasarrufu sağlaması ile yapı maliyetini azalttığ 1 ifade edilmiştir [4]. Padfield, hafif yap1 malzemesi üretiminde perlit, kil ve bentonit karışımından mükemmel şekil alan malzemeler üretmiş, deneylerde kullanılan kilin, perlit yüzeylerine homojen şekilde yayılarak basınç artışı sağladığı ifade edilmiştir [5]. Shi ve ark. tarafından yapılan çalışmada bağlayıcı olarak Portland çimentosu, mineralojik atık olarak cam tozu ve uçucu külün kullanıldığ çalışmada, kimyasal ve fiziksel özellikler belirlenmiştir [6]. Low ve Beadoin, yüksek alüminalı çimento, doğal volastonit lifleri ve silis dumanı kullanıldığında çimento örneklerinin eğilme dayanımının arttığını ve BHA değerlerinin azaldığını belirtmişlerdir [7]. Bunların yanı sıra Jamei ve ark. tarafından kırılabilir yumuşak parçacıklı doymamış malzemenin su tutma özelliklerine ait deneysel çalışmalar yapılmış, yüksek kırılabilirlik ve yüksek su depolama özelliklerinden ötürü suni malzeme olarak perlit kullanılmıştır. Neticede su geçirgenliği üzerinde kırılganlığın önemli olduğu belirtilmiştir [8]. Won ve ark. pek çok beton yapıların onarılmasında kullanılması öngörülen yüksek ısıl kararlılığa sahip genleştirilmiş perlit ve polipropilen elyaf karışımının birinci sınıf fiziksel, mekanik ve isıl özelliklere sahip olduğunu belirlemiştir [9]. Benk ve Coban, yaptıkları çalışmada; çimento ya da alçı türünde bağlayıcı kullanmaksızın pomza ve/veya genleştirilmiş perlit gibi hafif agregalardan hafif, 1sı yalıtımlı, su geçirmez ya da su itici malzemeler geliştirmişlerdir [10]. Munoz ve ark. dış duvarların ısıl davranışı konusunda en önemli faktörlerden birinin tuğla kilin 1sıl iletkenliği olduğunu, ateş kilinin ısıl ve mekanik özellikleri üzerinde kağıt hamurunun iletkenliği iyileştirdiğini dile getirmişlerdir [11]. Karakoç yaptığ çalışmada, genleştirilmiş perlit agregası ve pomza agregasından müteşekkil betonun basınç dayanımındaki değişimlerin soğuma ortamına bağlı olduğunu ifade etmiştir [12]. Ülkemizde inşaat endüstrisinde hafif yap1 malzemeleri üretimi üzerine yapılan bilimsel çalışmalar ve araştırmalar giderek artmaktadır. Ancak, yapılan çalışmalarda genleştirilmiş perlitin ana hammadde olarak kullanıldığı bir çalışmaya rastlanmamıştır. Bununla birlikte benzer tarzda yap1 malzemesi üretimi ve karakterizasyonuna yönelik yapılan çalışmalar mevcuttur $[13,14]$. Bu çalışma kapsamında düşük birim ağırlık ve yüksek basınç dayanımına sahip yapı malzemesi (kontrol numunesi) üretimi için optimizasyon parametreleri belirlenmiştir. Bu amaçla, genleştirilmiş perlit kullanılarak farklı karışım grupları elde edilmiş ve farklı sıcaklıklarda pişirilerek optimum değerler tespit edilmiştir. Ayrıca, optimum değerlere göre üretilen nihai numunelerin perlit (\%90), kömür tozu (\%5), CMC (\%5) bileşimli ve s/k oranı 1,0 ve 50 bar) fizikomekanik ve kimyasal özellikleri belirlenmiştir.

\section{MALZEME VE YÖNTEM (MATERIAL AND METHOD)}

\subsection{Malzeme (Material)}

Yap1 malzemesi (tuğla) üretiminde ana hammadde olarak genleştirilmiş perlit kullanılmıştır. Genleştirilmiş perlit kumu Eti Maden İşletmeleri İzmir (Cumaovası) perlit yataklarından temin edilmiş olup burada bulunan fabrika firınlarında $800^{\circ} \mathrm{C}$ sıcaklıkta genleştirilerek perlit tuğla üretiminde kullanılabilir hale getirilmiştir. Alınan numuneler işletmede $(0,2-2 \mathrm{~mm})$ boyut ve $\left(150-180 \mathrm{~kg} / \mathrm{m}^{3}\right)$ yoğunluğa gelecek şekilde genleştirilmiştir. Genleştirilmiş perlit kumunun birim hacim ağırlığı (BHA) $0,23 \mathrm{gr} / \mathrm{cm}^{3}$, yoğunluğu $1,973 \mathrm{~g} / \mathrm{cm}^{3}$ ve su emme değeri \%71,2 bulunmuştur. Deneylerde kullanılan Karboksimetilselüloz (CMC) Merck firmasından alınmıştır. Deneylerde kimyasal bağlayıcı olarak kullanılan CMC, sıkıştırma esnasında şekil vererek doğal kurumayı sağlamak ve pişmeye kadar numunelerin bozulmasinı engellemek amaciyla kullanılmıştır. Pişme sıcaklığını düşürmek amacıyla kullanılan kömür tozu Set Çimento Fabrikasından temin edilmiştir. Laboratuvarda öğütüldükten sonra 1 mm'lik elekten geçirilerek içindeki süreksizlikler uzaklaştırılmış ve katkı malzemesi olarak kullanılmıştır. Bu çalışmada karışım suyu olarak normal içme suyu şebekesinden alınan $20^{\circ} \mathrm{C}$ sıcaklıktaki su kullanılmıştır. Tablo 1'de deneylerde kullanılan malzemelerin özellikleri verilmiştir. TS EN 933-1'e göre yapilan tane boyut elek analizlerinin neticesinde, Şekil 1'de granülometri eğrisi verilen, Menderes genleştirilmiş perlitlerinin tuğla, beton, hafif yapı ve inşaat sektöründe kullanılmasında hiçbir sakınca görülmediği tespit edilmiştir.

Tablo 1. Deneylerde kullanılan malzemelerin özellikleri (Properties of materials used in experiments)

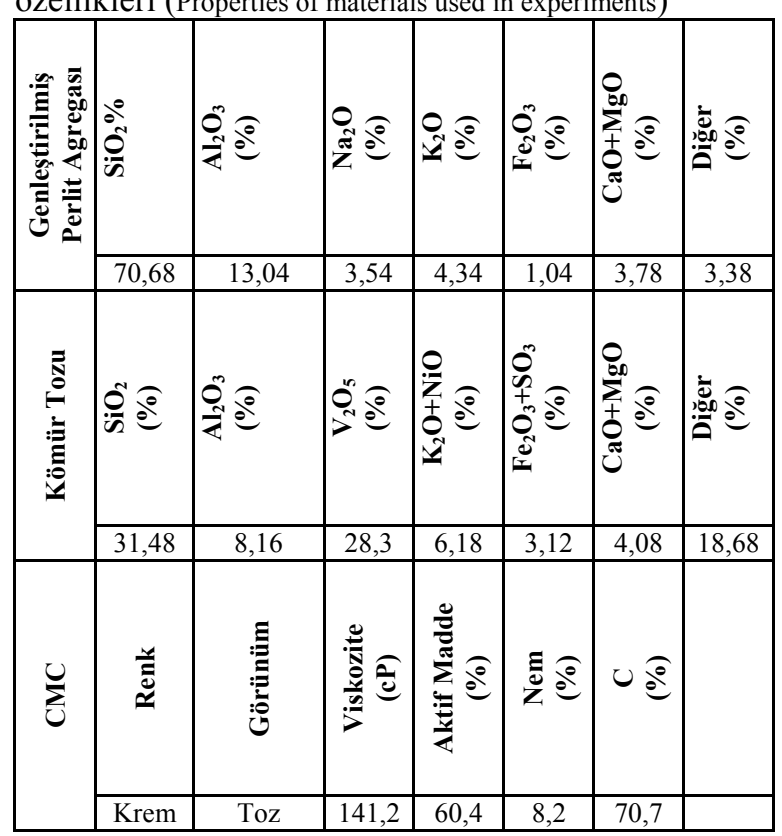




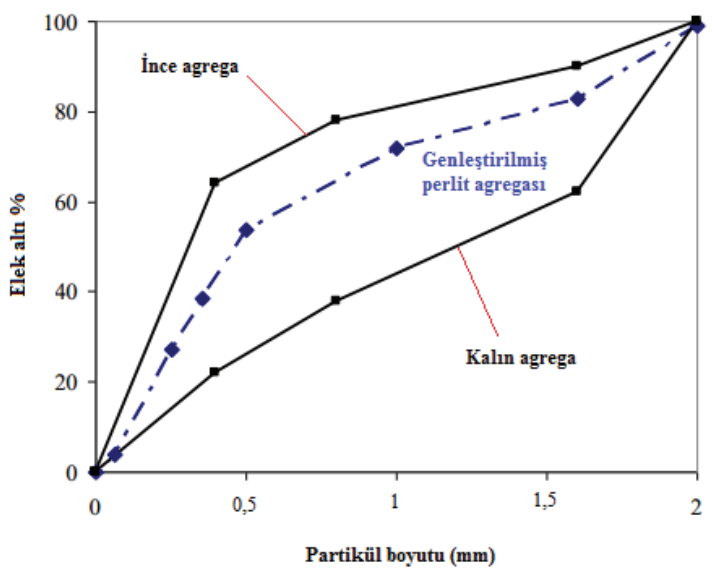

Şekil 1. Genleştirilmiş perlit agregasının granülometri eğirisi (Granulometry curve of the expanded perlite aggregate)

\subsection{Yöntem (Method)}

Tuğla üretim çalışmalarının ilk aşamasında, bağlayıcı kullanmadan üretim parametrelerinin (pişme sıcaklığı, karışım süresi, su/katı (s/k) oranı, CMC katkı miktarı ve numune basınç oranı) optimizasyonu TS EN 771-1 standardına uygun olarak yapılmıştır. Ana hammadde olarak $2 \mathrm{~kg}$ civarında genleştirilmişmiş perlit agregası, kimyasal katkı ve su ile birlikte mekanik karıştırıcı vasıtasıyla $30 \mathrm{dk}$. karıştırılarak 50x100x100 mm ebadında ikili kalıplara dökülerek numuneler üretilmiştir (Şekil 2). Numuneler yüksek sicaklık firınında pişirilerek deneylere hazır hale getirilmiştir. Her bir deneyde ortalama 10 adet numune kullanılmıştır. Tuğla üretiminde yüksek basınç, düşük BHA değerlerini veren $\mathrm{s} / \mathrm{k}$ oranı $(1,0,1,1,1,2), \mathrm{CMC}$ katkı miktarı $(\% 1,5,10)$, sıkıştırma basıncı $(40,50$, 60,70 bar) ve pişme sıcaklığı değerleri belirlenerek üretim optimize edilmiștir. Sıkıștırma sonrası üretilen malzemelerin yaş ve 24 saat sonra ortam sıcaklığındaki kuru BHA değerleri belirlenmiştir.

a)

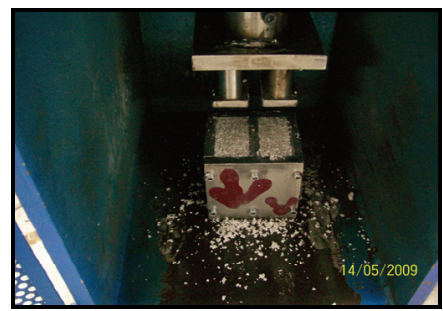

b)

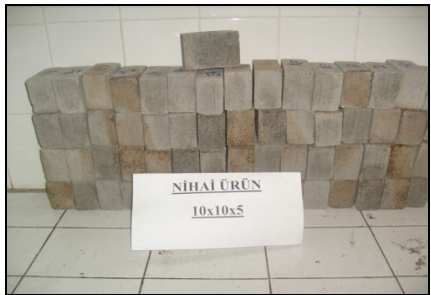

Şekil 2. Karışım malzemesinin preslenmesi (a) ve tuğlaların görünümü (b) (Pressing of mixing material (a) and view of the bricks (b))
Laboratuvar şartlarında (doğal ortamda) bir gün bekletilen numuneler yüksek sıcaklık firınında 200, 300 ve $400^{\circ} \mathrm{C}$ sicaklıklarda 1 saat süreyle pişirilmiş ve her bir pişme sıcaklığında BHA ve basınç değerlerindeki değişim kaydedilmiştir. Numunelerin 2 gün bekleme süresi sonunda fizikomekanik özellikleri belirlenmiştir. Pişme sıcaklığında $500-600^{\circ} \mathrm{C}$ ye kadar çıkılmış ancak ana hammadde olarak kullanılan genleştirilmiş perlitin yandığı ve basınç değerlerinin oldukça düştüğü görülmüştür. Pişme süresi denemeler ve literatürden elde edilen bilgilere göre belirlenmiştir. Tuğla üretim çalışmalarının ilk aşamasında, doğal (mineral) bağlayıcı kullanmadan, CMC'nin suyla reaksiyonu sağlanarak yapılmıştır. Birim hacim için tasarlanan karışım oranları Tablo 2 'de verilmiştir.

Tablo 2. Tuğla karışım oranları (Ratio of brick mixtures)

\begin{tabular}{ccccc} 
No & $\begin{array}{c}\text { Perlit } \\
(\%)\end{array}$ & $\begin{array}{c}\text { Kömür } \\
\text { Tozu } \\
(\%)\end{array}$ & $\begin{array}{c}\text { CMC } \\
(\%)\end{array}$ & $\begin{array}{c}\text { Su } \\
(\%)\end{array}$ \\
\hline Kontrol & 95 & 5 & - & $1,0-1,1-1,2$ \\
1 & 94 & 5 & 1 & 1,0 \\
2 & 90 & 5 & 5 & 1,0 \\
3 & 85 & 5 & 10 & 1,0 \\
\hline
\end{tabular}

Deneylerde kullanılan pres makinesi (200 bar basınç), karıştırıcı $\left(0,5-1 \mathrm{dm}^{3}\right.$ hacimli), tuğla kalıp ve başlıkları çalışmalarda kullanılmak üzere özel tasarlanmıştır. Üretilen numuneler $1200^{\circ} \mathrm{C}$ sicaklığa çıkabilen firın vasıtasıyla pişirilmiştir. Numune üretimi TS EN 771-1 standardına uygun olarak gerçekleştirilmiştir [15].

Üretilen numunelerin sonik dalga hızı ve ses yalıtım deneyleri ISRM (1981)'e göre (7, 14, 28 ve 90 gün) yaşlarında bekletilerek gerçekleştirilmiş [16], BHA ve su emme deneyleri TS 3529 [17], granülometri analizleri TS EN 933-1 [18], basınç dayanımı ve porozite deneyleri TS 699 [19] ve 1S1 iletim deneyleri TS 825 'e [20] göre yapılmıştır. Numunelerinin tek eksenli basınç dayanımı deneyleri; $5000 \mathrm{~kg}$ yük kapasiteli, $1 \mathrm{~kg}$ hassasiyette, $50 \mathrm{~mm} / \mathrm{dk}$ yükleme hızıyla hareket eden, dijital göstergeli cihaz kullanılarak gerçekleştirilmiştir. Sonik dalga hızı ölçümleri; RS 232 model, mekanik sinyali elektrik sinyale dönüştüren bir alıcı, elektronik sinyalleri mekanik sinyallere dönüştüren bir verici kullanılarak yapılmıştır. Tuğlaların ses yalıtım deneylerinde, ses seviyesi ölçer olarak, DT-8820 model dijital dB metre kullanılmıştır. Tuğlaların ısı iletim katsayısı (W/mK) değerleri, İzmir Yüksek Teknoloji Enstitüsü (IYTE) laboratuvarında bulunan KEMQTM 500 cihazı kullanılarak belirlenmiştir. Numunelerin kalitatif mineralojik analizleri (XRD-Cu X-ışın tüplü Rigaku Geigerflex) cihazında, Taramalı Elektron Mikroskop analizleri (SEM-FEI Quanta 400 MK2) elektron mikroskop altında SE (görüntü analiz sisteminde ve Elementel Analiz (EDS- EDAX Genesis XM 4i) 
model detektör kullanılarak Maden Tetkik Arama Genel Müdürlüğü (MTA) laboratuvarlarında gerçekleştirilmiştir.

\section{BULGULAR ve TARTIŞMA (RESULTS AND DISCUSSION)}

\subsection{Tuğlaların Fizikomekanik Özellikleri (Physicomechanical Properties of Bricks)}

\subsection{1 s/k oranın belirlenmesi (Determination of $\mathrm{s} / \mathrm{k}$ ratio)}

Kontrol numunesi karışım hesaplarında s/k oranı ve sıcaklık değişimine göre Şekil 3'de BHA, Şekil 4'de basınç dayanımı ve Şekil 5'de sonik dalga hızı ölçüm değerleri verilmiştir.

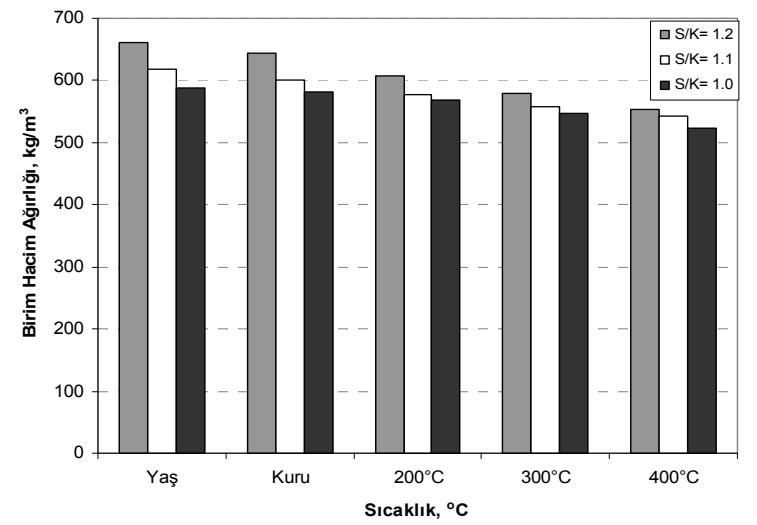

Şekil 3. Tuğlaların s/k oranına göre, sıcaklık ve BHA değişimi (Temperature and weight per unit of volume (WPUV) variation of bricks with respect to $\mathrm{w} / \mathrm{s}$ ratio)

Kontrol numunesi olarak üretilen tuğlaların ideal $\mathrm{s} / \mathrm{k}$ oranına göre en yüksek basınç ve en düşük BHA değerlerini veren örnekler kontrol numunesi olarak kabul edilmiştir. Kontrol tuğla numunesinin BHA değerleri, pişme sıcaklığının artması ile azalmakta ve su katkı miktarının artması ile doğru orantılı olarak artmaktadır (Șekil 3). $\mathrm{s} / \mathrm{k}$ oranının 1,0 olduğu durumda en düşük BHA değeri $\left(522,5 \pm 48,3 \mathrm{~kg} / \mathrm{m}^{3}\right)$ elde edilmiştir.

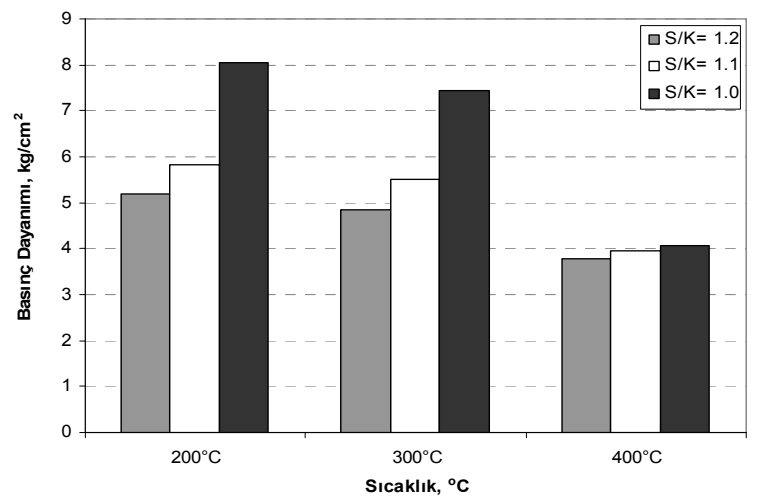

Şekil 4. Tuğlaların $\mathrm{s} / \mathrm{k}$ oranına göre, sıcaklık ve basınç dayanımı değişimi (Temperature and compressive strength variation of bricks with respect to $\mathrm{w} / \mathrm{s}$ ratio)
Ayrıca, pişme sıcaklığının artmasıyla basınç değerlerinin giderek azaldığ 1,0 ve $200^{\circ} \mathrm{C}$ sicaklıkta pişirilen numunelerden iyi basınç dayanımı değerleri $\left(8,1 \pm 0,38 \quad \mathrm{~kg} / \mathrm{cm}^{2}\right)$ gözlemlenmiştir (Şekil 4).

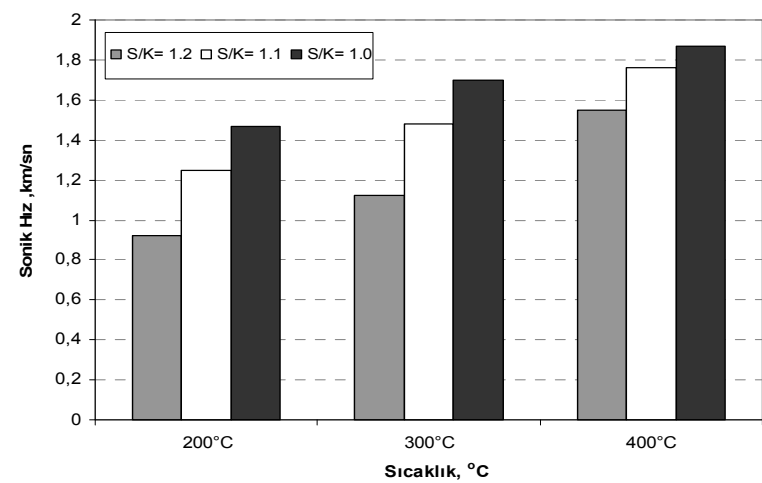

Şekil 5. Tuğlaların s/k oranına göre, sıcaklık ve sonik hız değişimi (Temperature and sonic velocity variation of bricks with respect to $\mathrm{w} / \mathrm{s}$ ratio)

Sonik dalga hızı değerleri sıcaklık artışı ile orantılı olarak artmaktadır. s/k oranı 1,2 olan numunelerde en düşük değerler $(0,92 \pm 0,02 \mathrm{~km} / \mathrm{sn})$ elde edilmiştir (Şekil 5).

\subsubsection{Bağlayıcı katkı oranın belirlenmesi (Determination of additive ratio of binder)}

CMC kullanım miktarı, tuğla basıncı, ağırlığı ve maliyeti açısından oldukça önemlidir. CMC katkı yüzdesinin, üretilen tuğla numunesinin BHA üzerine etkisi Şekil 6'da ve basınç üzerine etkisi Şekil 7'de verilmiștir.

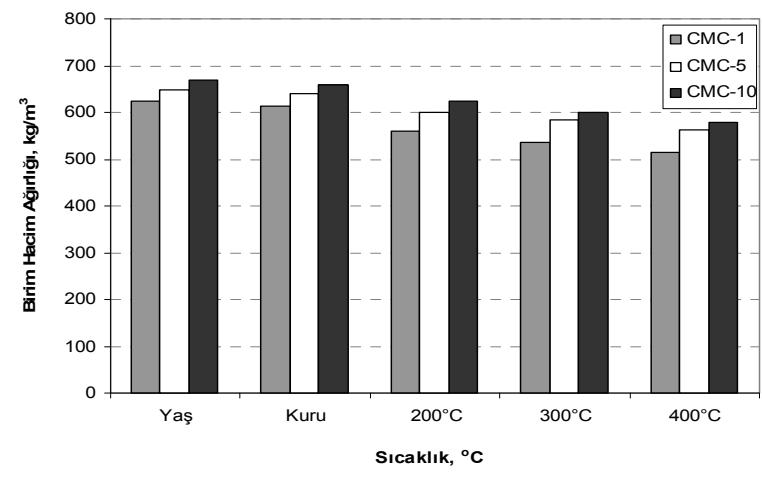

Şekil 6. Tuğlaların CMC katkı oranına göre sıcaklık ve BHA değişimi (Temperature and WPUV variation of bricks with respect to $\mathrm{CMC}$ additive)

CMC katkı miktarının artmasıyla numunelerin BHA değeri artmakta ve sıcaklık artışıyla ters orantılı olarak azalmaktadır. En iyi BHA değeri \%1 CMC katkılı ve $400^{\circ} \mathrm{C}$ sicaklıkta pişirilen numunelerden $\left(515 \pm 13,9 \mathrm{~kg} / \mathrm{m}^{3}\right.$ )elde edilmiştir (Şekil 6).

Kontrol tuğla olarak üretilen numunelerin CMC katk1 miktarına göre sıcaklık ve basınç dayanımı değişim 
değerleri incelendiğinde; katkı miktarının ve pişme sıcaklığının artmasıyla tuğla basınç dayanımı değerinin düştüğü ve en yüksek basınç değeri $200^{\circ} \mathrm{C}$ pişme sıcaklığında elde edilmiştir. \%5 CMC katkılı olarak üretilen numunelerin tüm pişme sıcaklıklarında en yüksek basınç dayanımı değerlerini $\left(10,93 \pm 0,37 \mathrm{~kg} / \mathrm{cm}^{2}\right)$ verdiği belirlenmiştir (Şekil 7).

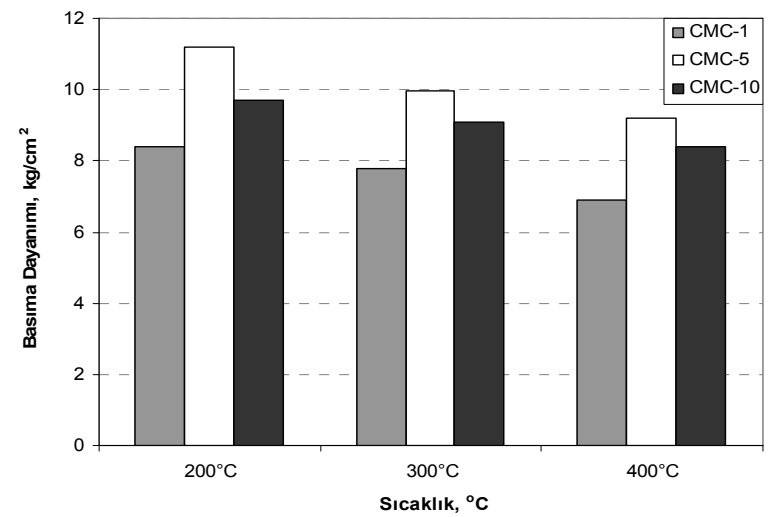

Şekil 7. Tuğlaların CMC katkı oranına göre sıcaklık ve basınç dayanımı değişimi (Temperature and compressive strength variation of bricks with respect to $\mathrm{CMC}$ additive)

\subsubsection{Sıkıştırma basınç değerinin belirlenmesi (Determination of pressing pressure value)}

Karışım üzerinde uygulanacak sıkıştırma basıncının düșük olması tuğla basınç dayanım değerinin düşmesine, yüksek olması ise tanelerin fazla ezilmesine, 1s1 ve ses geçirgenliği gibi mühendislik özelliklerinin zayıflamasına neden olmaktadır. Sıkıștırma basınç değerinin belirlenmesi amacıyla BHA değeri, basınç dayanımı, sonik dalga hızı, su emme ve porozite deney sonuçları sırasıyla (Şekil 8, 9, 10,11 ve 12)'de verilmiştir.

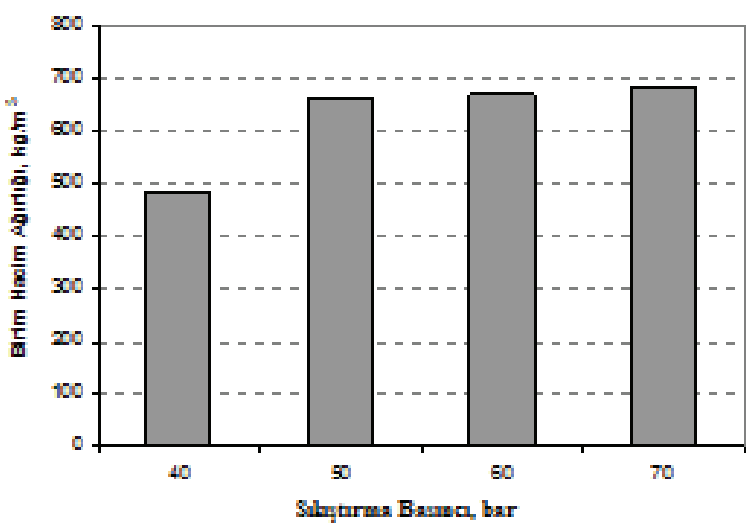

Şekil 8. Tuğlaların sıkıştırma basınç değerlerine göre BHA değişimi (WPUV variation of bricks with respect to CMC additive)

Sıkıştırma basınç değerinin artmasıyla tuğlaların birim hacimlerinde bir artış meydana geldiği $\left(664 \pm 22,0 \mathrm{~kg} / \mathrm{m}^{3}\right)$, ancak 50 bar basınçtan sonraki artış miktarının ise çok fazla olmadı̆̆ı belirlenmiştir (Şekil 8).

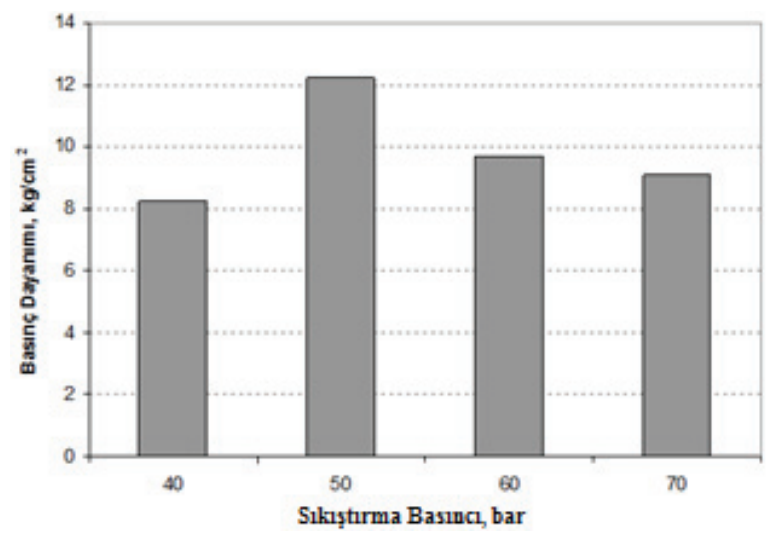

Şekil 9. Tuğlaların sıkıştırma basınç değerlerine göre basınç dayanımı değişimi (Compressive strength variation of bricks with respect to pressing values)

Şekil 9 incelendiğinde, 50 bar basınçta üretilen tuğlaların en yüksek basınç dayanımını sağladığı $\left(12,13 \pm 0,13 \mathrm{~kg} / \mathrm{m}^{3}\right)$ ve sıkıştırma basıncının artmasiyla numunelerin tek eksenli basma dayanımlarının giderek azalmaya başladığı tespit edilmiştir.

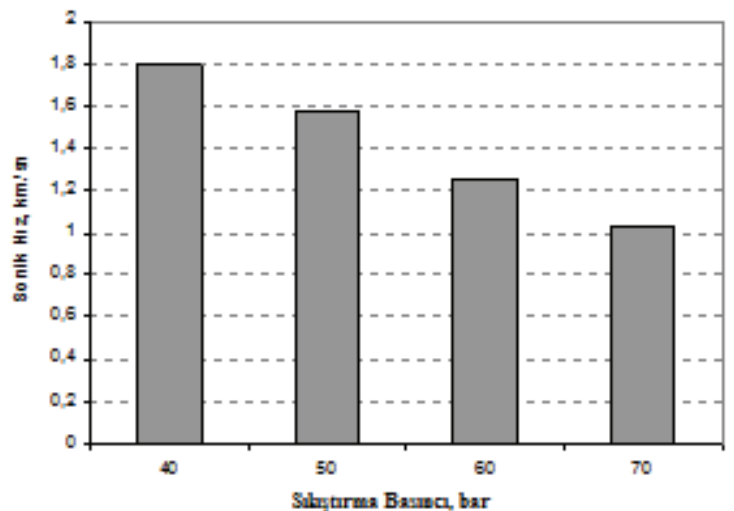

Şekil 10. Tuğlaların sıkıştırma basınç değerlerine göre sonik hız değişimi (Sonic velocity variation of bricks with respect to pressing values)

Sıkıştırma basıncının artmasıyla sonik dalga hızı ölçüm değerleri ters orantılı olarak azalmaktadır (Şekil 10).

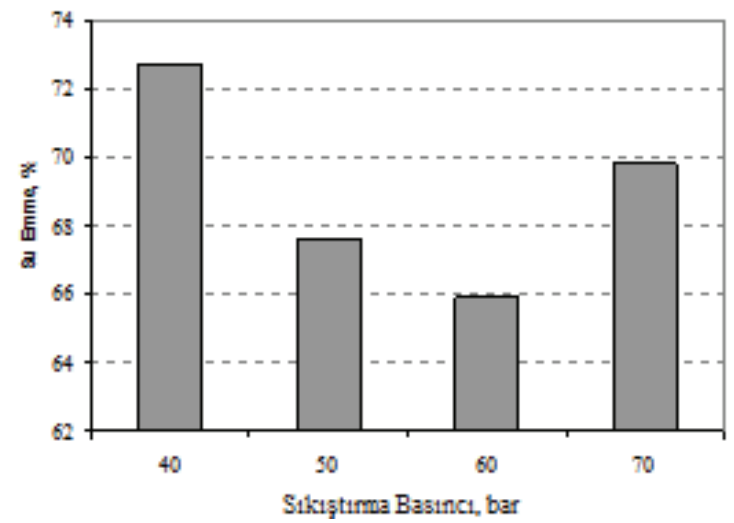

Şekil 11. Tuğlaların sıkıștırma basınç değerlerine göre su emme değişimi (Water absorption variation of bricks with respect to pressing values) 


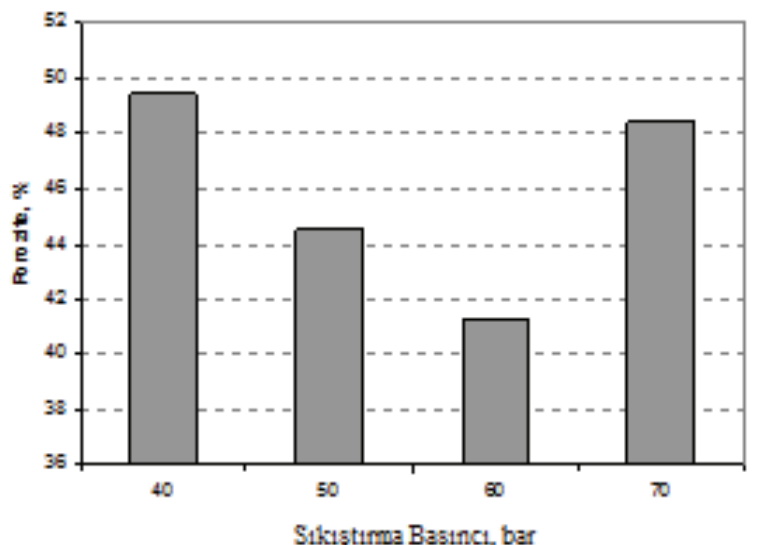

Şekil 12. Tuğlaların sıkıştırma basınç değerlerine göre porozite değişimi (Porosity variation of bricks with respect to pressing values)

Laboratuar çalışmalarında 50 ve 60 bar basınçta üretilen tuğlalarda en uygun su emme $(\% 65,9 \pm 3,4)$ ve porozite $(\% 41,3 \pm 2,4)$ değerlerinin elde edildiği ve bu değerlerin sıkıştırma basıncının artmasıyla giderek yükseldiği görülmüştür (Şekil 11,12).

\subsubsection{Isı iletim katsayısı ve ses geçiş kaybı değerleri (Heat transfer coefficients and sound pass loss values)}

Yap1 sektöründe kullanılan tuğlalar taşıyıcı olmayıp bölme elemanı olarak kullanıldıklarından yüksek basınç dayanım özelliği istenmemektedir. Bu amaçla, üretilen tuğlaların 1sı iletim katsayısı ve ses geçirgenlik değerlerinin belirlenmesi ve çıkan sonuçların karşılaştırılması önem arz etmekte olup tuğlaların zamana bağlı isı ve ses deney sonuçları Şekil 13'te verilmiştir.
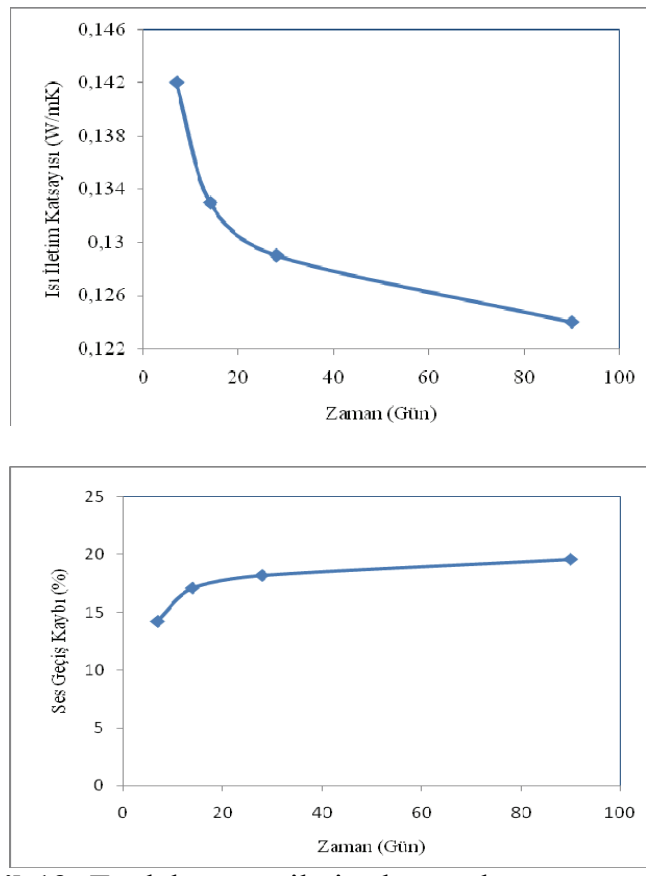

Şekil 13. Tuğlaların 1sı iletim katsayıları ve ses geçiş kayb1 (Heat transfer coefficients of bricks and sound passing loss of bricks)
Nihai ürünlerin 1sı iletim katsayı değerlerinin zamanla az miktarda iyileştiği ve 1sı iletim değerlerinin 90 günlük zaman dilimindeki numunelerde en iyi sonuçları $(0,12 \mathrm{~W} / \mathrm{mK})$ verdiği belirlenmiştir. Ses yalıtım değerlerinin 2-28 gün aralığında düşük oranda arttığ 1 ve 90 . günde optimum değere $(\% 19,6)$ ulaştığ 1 belirlenmiştir.

\subsection{Mikroyapı ve Minerolojik Analizler \\ (Microstrutural and Mineralogical Analysis)}

SEM analizleri neticesinde; $200^{\circ} \mathrm{C}$ sicaklıkta pişirilen numunelerin camsı yapıda olduğu ve $300^{\circ} \mathrm{C}$ sıcaklıkta pişirilen numunelerin kırılma yüzeyleri ile birlikte balon şeklinde yapıların geliştiği görülmektedir. $400^{\circ} \mathrm{C}$ civarında pișirilen numunelerde bu balonsu yapılar artmakta ve misır patlağı gibi kırılarak gözenekli yapı oluşmaktadır (Şekil 14).

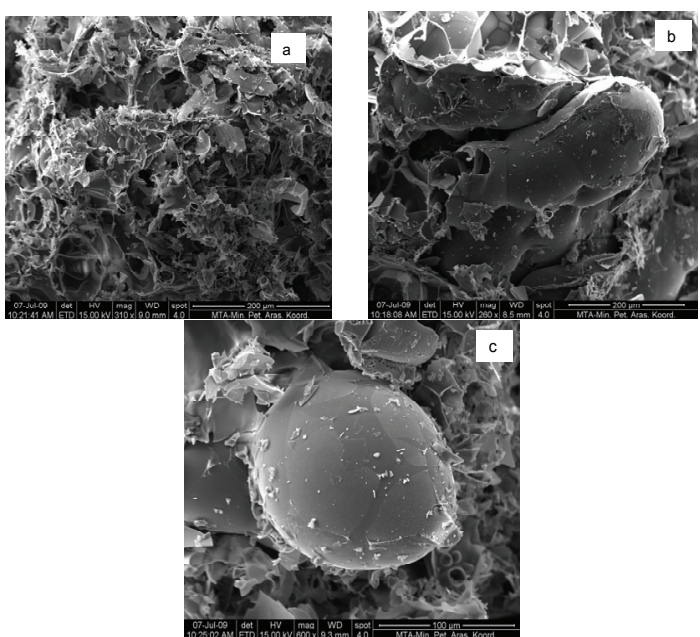

Şekil 14. Numunelerin farklı pişme sıcaklığındaki SEM görüntüleri (a: $200^{\circ} \mathrm{C}, \mathrm{b}: 300^{\circ} \mathrm{C}$ ve c: $400^{\circ} \mathrm{C}$ ) (SEM images of samples at various temperatures $\left(\mathrm{a}: 200^{\circ} \mathrm{C}\right.$, b: $\left.\left.300^{\circ} \mathrm{C}, \mathrm{c}: 400^{\circ} \mathrm{C}\right)\right)$

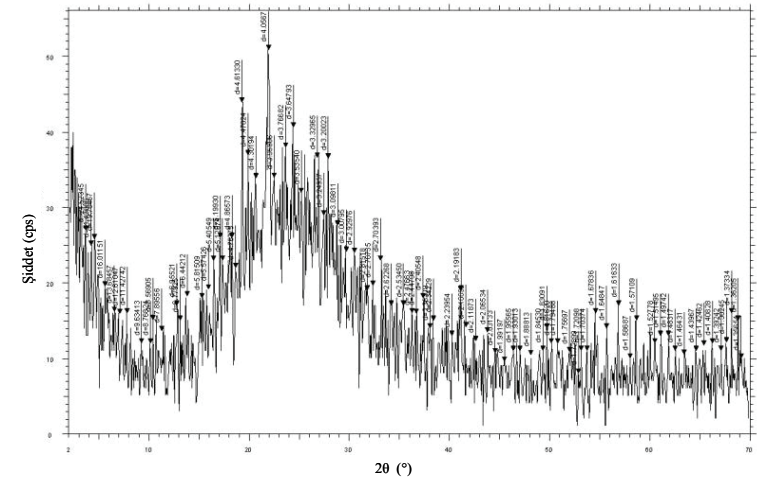

Şekil 15. Numunelerin $400^{\circ} \mathrm{C}$ pişme sıcaklığında Xray difraktometre analizi sonuçları (X-Ray Diffactrometer analysis results of samples at a burning temperature of $400^{\circ} \mathrm{C}$ )

Analiz sonuçlarına göre tuğla bünyesinde kristobalit, tridimit ve kuvars minerallerinin varlığına rastlanmıştır (Şekil 15). 


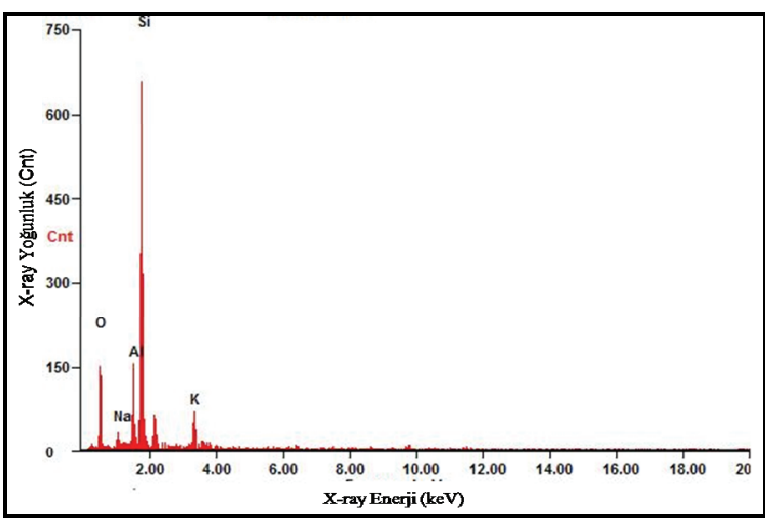

Şekil 16. Numunelerin $400^{\circ} \mathrm{C}$ pişme sıcaklığında EDS analizi sonuçları (EDS analysis results of samples at a burning temperature of $400^{\circ} \mathrm{C}$ )

EDS analizlerinin sonucunda numune bünyesinde silisyum $(\% 45,13)$, oksijen $(\% 38,91)$, alüminyum $(\% 8)$, potasyum $(\% 5,58)$ ve sodyum $(\% 2,37)$ elementlerinin olduğu tespit edilmiştir (Şekil 16).

\section{SONUÇLAR (CONCLUSIONS)}

1. En düşük BHA değeri, $\% 1 \mathrm{CMC}$ katkılı ve $400^{\circ} \mathrm{C}$ sıcaklıkta pişirilen, en yüksek basınç dayanımı değerleri ise $\% 5 \mathrm{CMC}$ katkılı ve $200{ }^{\circ} \mathrm{C}$ 'de pişirilen numunelerden elde edilmiştir. Bağlayıcı kullanarak üretilen numunelerin basınç dayanım değerleri kontrol numunesinden elde edilen değerlere kıyasla \% 49,75 artmıştır.

2. Pişme sıcaklığının artmasıyla BHA ve basınç dayanımı değerleri azalmakta ve sonik dalga hızı değerleri artmaktadır.

3. Sıkıştırma basıncının artmasıyla numunelerin BHA, su emme ve porozite değerlerinde artış meydana geldiği, numunelerin basınç dayanımlarının giderek azalmaya başladığı belirlenmiştir.

4. Numunelerin en yüksek 1sı iletim katsayı ve ses yalıtım değerlerine 90. günde ulaşıldığ 1 tespit edilmiştir.

İlerleyen aşamalarda farklı bağlayıcıların (doğal mineral/kimyasal) katkılanabileceği yüksek mukavemet ve düşük BHA değerlerine sahip yapı malzemesi üretimine yönelik bilimsel çalışmaların yapılması oldukça önemlidir.

\section{TEŞEKKÜR (ACKNOWLEDGEMENT)}

Yazarlar, bu çalışma kapsamında sağladığı destekten dolayı, Ulusal Bor Araştırma Enstitüsüne (Proje no: 2008-BO201) teșekkür eder.

\section{KAYNAKLAR (REFERENCES)}

1. Çelik, A.G., Bor Katkılı Perlit Karıșımlardan Hafif Tuğla Üretimi ve Teknolojik Özelliklerinin Belirlenmesi, Doktora Tezi, Çukurova Üniversitesi, Fen Bilimleri Enstitüsü, 2010.

2. Çelik, A.G., Kılıç, A.M. ve Çakal, G.Ö., "Expanded Perlite Aggregate Characterization For Use as a Lightweight Construction Raw Material", Physicochemical Problems of Mineral Processing, Cilt 49, No 2, 689-700, 2013.

3. Cobanlı, M.R., Isı Direnci Yüksek Hafif Yapı Malzemesi Üretimi, Yüksek Lisans Tezi, Osmangazi Üniversitesi, Fen Bilimleri Enstitüsü, 1993.

4. Ayberk, M., "Perlitin Yapı Gereci Olarak Kullanımı ve Yapı Maliyetine Etkisi”, Endüstriyel Hammaddeler Sempozyumu, İzmir, 203-206, 21-22 Nisan 1995.

5. http://www.conservationphysics.org/wallbuff/wal lbuff.php

6. Shi, C., Wu, Y., Riefler, C. ve Wang, H., "Characteristics and Pozzolanic Reactivity of Glass Powders", Cement and Concrete Research, Cilt 35, No 7, 987-993, 2005.

7. Low, N.M. ve Beadoin, J.J., "Mechanical Properties and Microstructure of High Alumina Cement- Based Binders Reinforced with Natural Wollastonite Micro-Fibres", Cement and Concrete Research, Cilt 24, No 4, 650-660. 1994.

8. Jamei, M., Guiras, H., Chtourou, Y., Kallel, A., Romero, E. ve Georgopoulos, I., "Water Retention Properties of Perlite as a Material with Crushable Soft Particles", Engineering Geology, Cilt 122, No 3-4, 261-271, 2011.

9. Won, J.P., Kang, H.B., Lee, S.J., Lee, S.W. ve Kang, J.W., "Thermal Characteristics of HighStrength Polymer-Cement Composites with Lightweight Aggregates and Polypropylene Fiber", Construction and Building Materials, Cilt 25, No 10, 3810-3819, 2011.

10. Benk, A. ve Coban, A., "Possibility of Producing Lightweight, Heat Insulating Bricks From Pumice and $\mathrm{H}_{3} \mathrm{PO}_{4}$ or $\mathrm{NH}_{4} \mathrm{NO}_{3}{ }^{-}$Hardened Molasses Binder", Ceramics International, Cilt 38, No 3, 2283-2293, 2012.

11. Munoz, P., Juárez, M.C., Morales, M.P. ve Mendívil, M.A., "Improving The Thermal Transmittance of Single-Brick Walls Built of Clay Bricks Lightened with Paper Pulp”, Energy and Buildings, Cilt 59, 171-180, 2013.

12. Karakoç, M.B., "Effect of Cooling Regimes on Compressive Strength of Concrete with Lightweight Aggregate Exposed to High Temperature", Construction and Building Materials, Cilt 41, 21-25, 2013. 
13. Demir, İ., “Alkali-Silika Reaksiyonu Etkisine Maruz Aynı Oranda Silis Dumanı ve Uçucu Kül İçeren Harçların Mekanik Özellikleri”, Journal of the Faculty of Engineering and Architecture of Gazi University, Cilt 25, No 4, 749-758, 2010.

14. Aydoğan, U., Bilen, M. ve Gürü, M., "Anortit Seramik Malzeme Üretiminde Uçucu Kül ve Borik Asitin Kullanılabilirliği”, Journal of the Faculty of Engineering and Architecture of Gazi University, Cilt 26, No 4, 761-769, 2011.

15. TS EN-771-1:Kagir Birimler-Tuğlalar, Deney Metodları, 2010.
16. Brown, E.T., Rock Characterisation, Testing and Monitoring, Pergamon Press, New York, A.B.D.,ISRM, 1981.

17. TS 3529, Beton Agregalarında Özgül Ağırlık ve Su Emme Oranı Tayini, Ankara,1980.

18. TS EN 933-1, Agregaların Geometrik Özellikleri İçin Deneyler Kısım 2: Tane Boyutu Dağılım Tayini-Deney Elekleri, Elek Göz Açıklıklarını Anma Büyüklükleri, Ankara, 1996.

19. TS 699, Muayene ve Deney Metotları, Ankara, 2009.

20. TS 825, Binalarda is1 yalıtım kuralları, 81s, Ankara,1998. 